\title{
Nanomaterials and Cross-Cutting Technologies for Fostering Smart Electrochemical Biosensors in the Detection of Chemical Warfare Agents
}

Fabiana Arduini 1,2

Citation: Arduini, F. Nanomaterials and Cross-Cutting Technologies for Fostering Smart Electrochemical Biosensors in the Detection of Chemical Warfare Agents. Appl. Sci. 2021, 11, 720. https://doi.org/ 10.3390/app11020720

Received: 16 December 2020 Accepted: 8 January 2021 Published: 13 January 2021

Publisher's Note: MDPI stays neutral with regard to jurisdictional clai$\mathrm{ms}$ in published maps and institutional affiliations.

Copyright: (C) 2021 by the author. Licensee MDPI, Basel, Switzerland. This article is an open access article distributed under the terms and conditions of the Creative Commons Attribution (CC BY) license (https:// creativecommons.org/licenses/by/ $4.0 /)$.
1 Department of Chemical Science and Technologies, Tor Vergata University, Via della Ricerca Scientifica, 00133 Rome, Italy; fabiana.arduini@uniroma2.it

2 SENSE4MED, Via Renato Rascel 30, 00128 Rome, Italy

\begin{abstract}
The smart, rapid, and customizable detection of chemical warfare agents is a huge issue for taking the proper countermeasures in a timely fashion. The printing techniques have established the main pillar to develop miniaturized electrochemical biosensors for onsite and fast detection of nerve and mustard agents, allowing for a lab on a chip in the chemical warfare agent sector. In the fast growth of novel technologies, the combination of miniaturized electrochemical biosensors with flexible electronics allowed for the delivery of useful wearable sensors capable of fast detection of chemical warfare agents. The wearable microneedle sensor array for minimally invasive continuous electrochemical detection of organophosphorus nerve agents, as well as the wearable paper-based origami functionalized with nanomaterials for mustard agents in the gas phase, represent two examples of the forefront devices developed in the chemical warfare agent detection field. This review will highlight the most promising electrochemical biosensors developed by exploiting nanomaterials and cross-cutting technologies for the fabrication of smart and sensitive electrochemical biosensors for the detection of chemical warfare agents.
\end{abstract}

Keywords: screen-printing; paper-based sensor; wearable sensors; nerve agents; mustard agents

\section{Introduction}

The electrochemical biosensor is defined as a chemical sensor constituted of a recognition element and an electrochemical transducer, in which the device is able to transform the biochemical information related to the interaction of the analyte with the recognition element into an electrochemically detectable signal [1]. The electrochemical biosensors are classified by the function of the biocomponent used (e.g., enzyme, antibody, DNA sequence) or the transducer (e.g., potentiometric, amperometric, voltammetric transducers). The customization of biosensors with suitable biocomponents and transducers has opened the possibility to develop diverse types of biosensors for the detection of the target analyte, belonging to several sectors, including the biomedical, environmental, and defence ones. The first biosensor applied in the defence field was developed by Guilbault et al. in 1962 [2], in which two platinum electrodes were selected as the transducer and the cholinesterase enzyme as a biocomponent for nerve agent detection. This biosensor was designed and merely inspired by nature, because the principle is based on how the nerve agents act on the human beings. Indeed, the toxicity of nerve agents relies on their ability to irreversibly inhibit a key enzyme of nervous transmission, namely acetylcholinesterase, and thus this enzyme was selected as a biocomponent and immobilized on the electrochemical transducer. By measuring the enzymatic activity before and after the exposure, the decrease in the response points out the presence of cholinesterase inhibitors, including nerve agents, and the percentage of decrease is proportional to the amount of nerve agent detected. This biosensor allowed for the detection of Sarin at concentration of $3 \mathrm{ng} / \mathrm{mL}$ using $10 \mathrm{~min}$ as incubation time, which is the time of reaction between enzyme and nerve agent, followed 
by the measurement of residual enzymatic activity. For the detection of nerve agents, two types of biosensors are mainly reported in the literature (Figure 1). The one most used relies on the use of cholinesterase as biocomponent, exploiting the capability of nerve agents to inhibit acetyl- and butyrylcholinesterase for a highly sensitive measurement. However, these biosensors are not specific because they generally detect organophosphorus compounds, working like a "family doctor" [3]. The cholinesterase biosensors are characterized by different degrees of sensitivity towards organophosphorus pesticides and nerve agents, in the function of inhibition properties. Furthermore, the inhibitive biosensors require an incubation step needed for a sensitive measure. This analytical tool can only be used once, unless a step with a reactivator compound is carried out after the nerve agent is measured [4]. The other approach is based on the use of organophosphate hydrolase enzyme able to hydrolyzed the organophosphorus compounds, thus detecting a nerve agent as the enzymatic substrate. This type of biosensor does not require a time of incubation, allowing for a faster measure than the one using a cholinesterase biosensor, but it is characterized by a lower sensitivity. For mustard agent detection, the most recent biosensors developed rely on the monitoring of inhibition using choline oxidase as the enzyme.

\section{Enzymatic biosensors for chemical warfare agents}

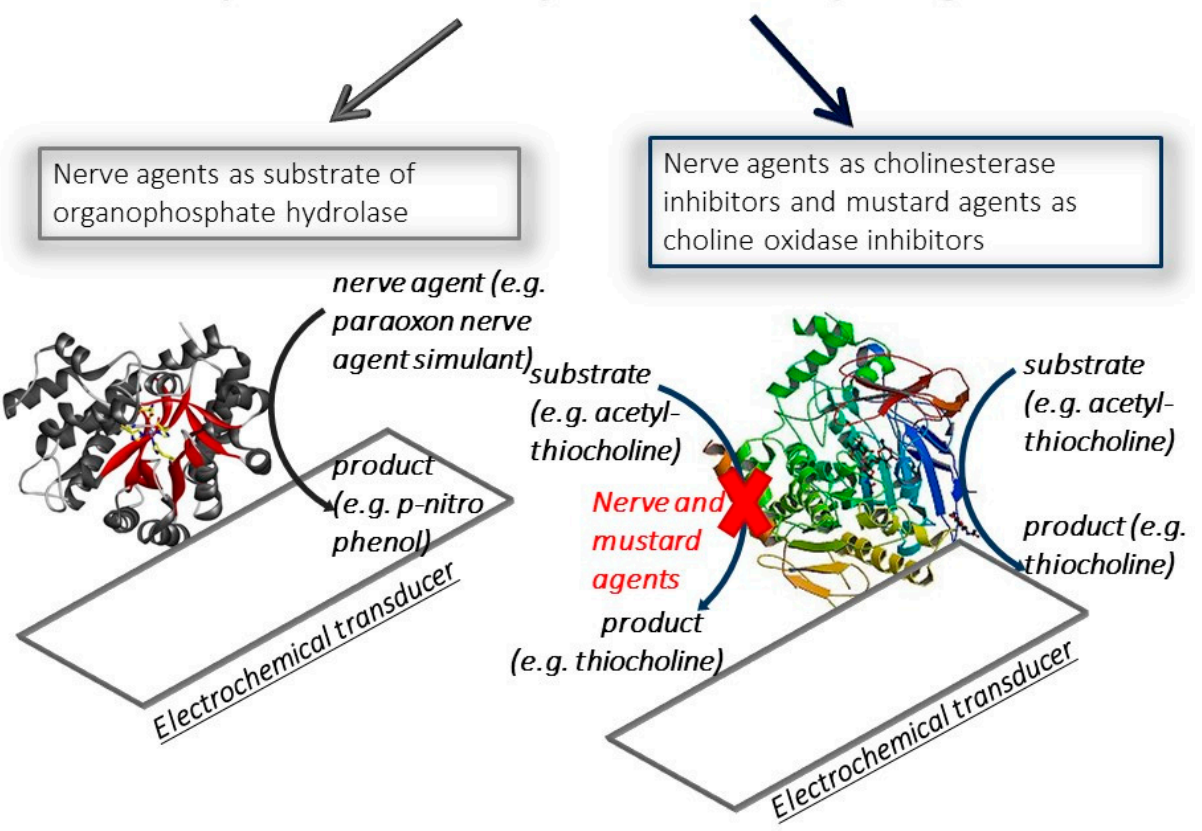

Figure 1. Scheme of enzymatic biosensor types for the detection of chemical warfare agents.

For a reliable, cost-effective, easy, and on-site measurement, the electrochemical transducers are among the most suitable candidates, being characterized by high sensitivity and capability to work in complex matrices. Electrochemical detection in the last years has undergone a growing period due to the exploitation of cross-cutting technologies, as reported by Escarpa "With the appearance of advanced approaches such as screen-printed technology, biosensors, microchips and nanotechnology, among others, electroanalysis is undergoing a true Renaissance" [5]. Indeed, printed technologies, also on paper, combined with nanomaterials and flexible electronics have boosted the development of devices with unprecedented features, namely high sensitivity, wireless connection, reagent-free measurement, and foldable sensors aiming to develop smart devices in different fields, including the defence one. The defence sector requires devices that are able to detect the chemical warfare agents fast, on site, and by easy procedures, to take the correct countermeasures in a timely fashion; thus, the electrochemical biosensors are useful and highly attractive analytical tools, with all features requiring the defence field. 
Herein, I report the literature related to the electrochemical biosensors for the detection of nerve and mustard agents to demonstrate how the cutting-edge technologies have boosted the development of smart analytical platforms for the reliable detection of these chemical warfare agents.

\section{Nanomaterials as Electrode Modifier to Boost the Biosensor Analytical Features}

The exploitation of nanomaterials in the different disciplines has allowed for the development of different products with improved features, rending the nanodimension one of the key features in the research and industrial sectors [6].

Searching in Google Scholar, the articles with the word "nanomaterial" and "electrochemical biosensor" in December 2020, more than 11,000 documents have been reported, demonstrating that the use of nanomaterials in the development of electrochemical biosensors is one of the determining research topics in the sensing field at the worldwide level.

In the sector of electrochemical biosensors for chemical warfare agents, the presence of nanomaterials has augmented the smart configurations of the devices with the development of analytical tools characterized by improved analytical features in terms of sensitivity, selectivity, and stability.

One of the first biosensors based on the use of nanomaterials for the detection of nerve agents was reported by Joshi et al. in 2005 [7], in which carbon nanotubes were used as a working electrode nanomodifier for the sensitive detection of acetylcholinesterase by-product. This biosensor was constructed by modifying the working electrode surface via drop casting with a dispersion of multiwalled carbon nanotubes at a concentration of $2 \mathrm{mg} / \mathrm{mL}$ in N,N-dimethylformamide. In detail, $15 \mu \mathrm{L}$ of this solution were dropped onto the electrode surface and then the modified electrode was kept in an oven at $80^{\circ} \mathrm{C}$ for 30 min under vacuum to allow for the evaporation of the solvent. After that, the acetylcholinesterase was dropped on the carbon nanotubes-modified electrode to immobilize the enzyme by physical adsorption. Rinsing twice with phosphate buffer allowed for the removal of the loosely adsorbed acetylcholinesterase molecules, leaving only the acetylcholinesterase molecules strictly bonded to carbon nanotubes. Being an amperometric monoenzymatic biosensor, acetylthiocholine was used as a substrate with the production of thiocholine as the enzymatic by-product. The amperometric detection of thiols is characterized by high voltage and the fouling problem, and indeed the detection of thiocholine at bare electrode happened at $+600 \mathrm{mV}$ vs. Ag pseudoreference, while the presence of carbon nanotubes allowed for detection at $+200 \mathrm{mV}$ with a stable signal, thus avoiding the fouling problem (Figure 2A). This biosensor was tested with paraoxon, used as model organophosphate nerve agents, with a detection limit of $0.5 \mathrm{nM}(0.145 \mathrm{ppb})$. The presence of carbon nanotubes demonstrated that this nanomaterial was used to immobilize the enzyme as well as to detect the enzymatic product at a low applied potential, thus avoiding the fouling issue.

Carbon black is a nanomaterial widely used in the detection of analyte in the liquid phase since 2020 [8], demonstrating its outstanding features, such as the improved electron transfer [9-11], resistance to the fouling [12,13], easiness to prepare a stable dispersion [14], compatibility with the biocomponent $[15,16]$, and cost-effectiveness (ca. 1 euro/kg). Carbon black was used to develop a biosensor for the detection of the same model compound (i.e., paraoxon) reported above, using a printed sensor modified with carbon black by drop casting $6 \mu \mathrm{L}$ of carbon black dispersion $1 \mathrm{mg} / \mathrm{mL}$ prepared in a solution of water $/ \mathrm{N}, \mathrm{N}$ dimethylformamide in a ratio of $1: 1(\mathrm{v} / \mathrm{v})$. The enzyme butyrylcholinesterase was selected to be immobilized onto the working electrode surface using a chemical immobilization through glutaraldehyde and Nafion ${ }^{\circledR}$ (Figure 2B). The choice of butyrylcholinesterase is due to improve storage stability of this biosensor in respect to the acetylcholinesterasebased one, being the biosensor able to detect the organophosphates even when stored at RT in a dry condition for several weeks [17]. In addition, the presence of carbon black is able to detect thiocholine at low applied potentials (i.e., $+300 \mathrm{mV}$ vs. $\mathrm{Ag} / \mathrm{AgCl}$ pseudoreference) 
without the fouling problem [18]. This biosensor detected paraoxon with a linear range up to $30 \mu \mathrm{g} \mathrm{L}{ }^{-1}$ and a detection limit of $5 \mu \mathrm{g} \mathrm{L}^{-1}$ [19].

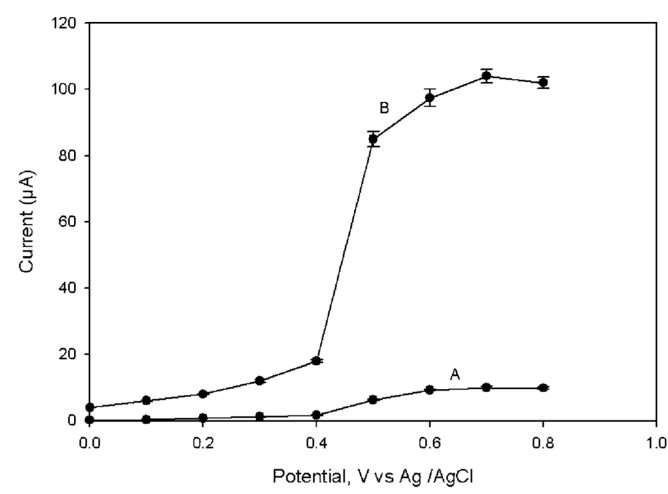

(A)

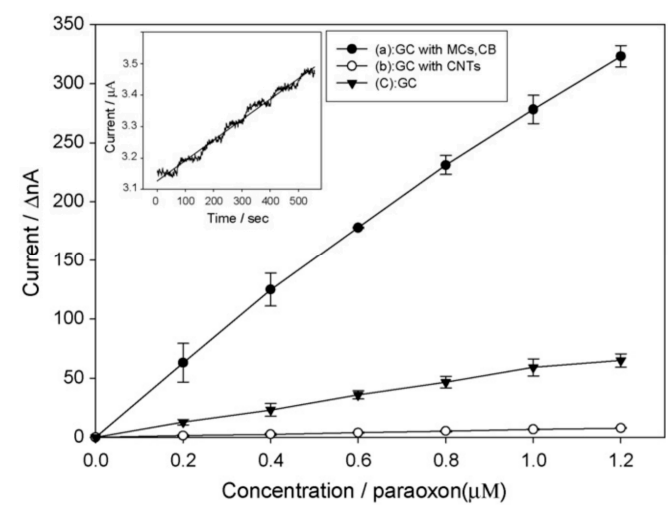

(C)

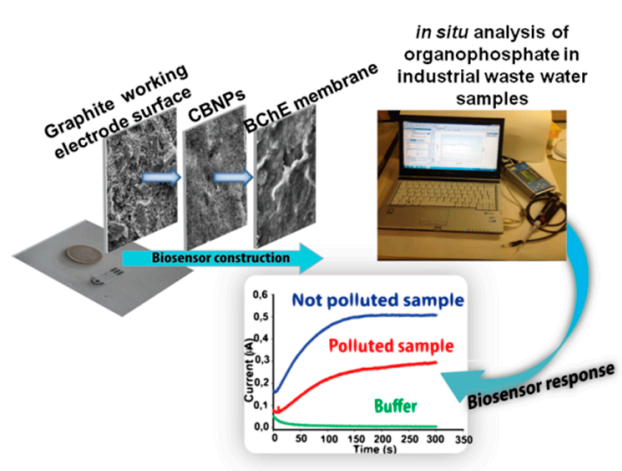

(B)

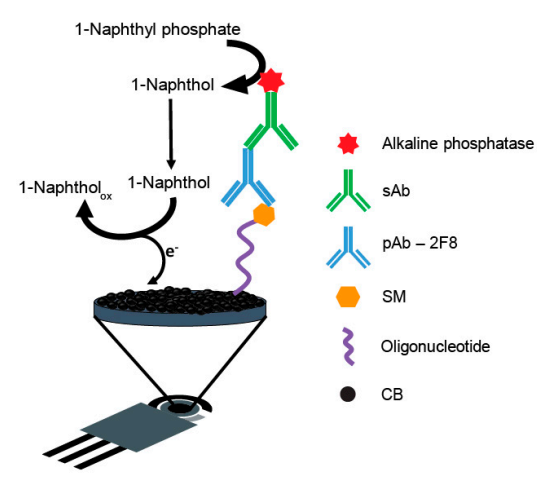

(D)

Figure 2. Biosensors based on nanomaterials for chemical warfare agent detection. (A) Study of applied potential using bare (A) and carbon nanotubes (B) modified electrode for the enzymatic byproduct thiocholine [7]. (B) Miniaturised biosensor based on carbon black for the detection of model organophosphate nerve agent paraoxon [19]. (C) Paraoxon detection using a mesoporous-carbon black biosensor and organophosphorus hydrolase as the biocomponent [20]. (D) The scheme of carbon black-based heterogeneous oligonucleotide-antibody assay for sulphur mustard detection [21].

Carbon black was also used, combined with mesoporous carbon, for nerve agents using organophosphorus hydrolase as a biocomponent. The biosensor was fabricated by modifying a glassy carbon electrode with the drop-casting approach with a dispersion of mesoporous carbon and carbon black. The organophosphorus hydrolase was immobilized onto the modified electrode with $\mathrm{Nafion}^{\odot}$ and the biosensor was dried at room temperature and kept in a refrigerator at $4{ }^{\circ} \mathrm{C}$. The presence of carbon black improved the sensitivity, as reported by the authors "by incorporating CB into the electrode, the sensitivity of the MC-modified electrode was heightened", even when compared to the electrode modified with carbon nanotubes (Figure 2C). Using the optimized experimental conditions, this biosensor allowed for the measurement of paraoxon with a sensitivity of $198 \mathrm{nA} / \mathrm{M}$ and a detection limit of $0.12 \mathrm{M}$ (36 ppb) [20].

Carbon black has recently been used to develop a heterogeneous oligonucleotideantibody biosensor for the detection of sulphur mustard (bis(2-chloroethyl)sulphide) [21]. The principle of the detection relies on the monitoring of the formation of a sulfur mustardoligonucleotide adduct on the surface of printed electrodes. After that, the immunoassay was carried out using a primary antibody for the selective recognition of the sulphur mustard-oligonucleotide adduct followed by an alkaline phosphatase-conjugated anti-IgG as the secondary antibody for the measurement of the immunological chain. In detail, 1-naphthyl phosphate was used as the substrate and the enzymatic product 1-naphthol 
was measured in differential pulse voltammetry using a carbon black-modified electrode with improved sensitivity with respect to the bare electrode. Under optimized conditions, this biosensor allowed for a linear range up to $80 \mathrm{mM}$ and a detection limit of $12 \mu \mathrm{M}$ of sulphur mustard.

In an old paper published in 1948 by Barron et al., the effect of mustard agents on enzymatic activity was investigated, revealing choline oxidase as the most sensitive enzyme by the inhibition of nitrogen mustards [22]. Inspired by this work, we developed a bioassay based on the inhibition property of mustard agents on choline oxidase. In detail, the enzymatic activity was monitored by measuring the hydrogen peroxide by-product. The detection of hydrogen peroxide was carried out using an electrode modified with Prussian Blue nanoparticles because this electrochemical mediator is able to electrocatalyze the reduction of hydrogen peroxide at a low applied potential, i.e., close to $0 \mathrm{~V} v \mathrm{vs}$ Ag/ $\mathrm{AgCl}$ pseudoreference. The outstanding electrocatalytic activity of Prussian Blue is well established in the literature, and for this reason it is also called "artificial peroxidase" [23]. The nanoparticles of Prussian Blue were chemically synthetized on the working electrode surface as follows: $5 \mu \mathrm{L}$ of $0.1 \mathrm{M}$ potassium ferricyanide in $10 \mathrm{mM} \mathrm{HCl}$ with $5 \mu \mathrm{L}$ of $0.1 \mathrm{M}$ ferric chloride in $10 \mathrm{mM} \mathrm{HCl}$ were drop-cast on the working electrode surface, the solution was left on the electrode for $10 \mathrm{~min}$, and then rinsed with a few millilitres of $10 \mathrm{mM} \mathrm{HCl}$. The electrodes were then left for $90 \mathrm{~min}$ in the oven at $100{ }^{\circ} \mathrm{C}$, allowing for an electrode modification with Prussian Blue nanoparticles with the dimensions of $95 \pm 15 \mathrm{~nm}$ [24]. The effectiveness of this novel bioassay was successfully verified with the nitrogen mustard simulant bis(2-chloroethyl)amine and the sulphur mustard simulants, i.e., 2-chloroethyl ethyl sulphide and 2-chloroethyl phenyl sulphide [25], demonstrating the suitability of a novel biosensor for the detection of sulphur mustard.

\section{Printing Technologies to Deliver Disposable and Miniaturised Devices}

Printing techniques have revolutionized electrochemistry because the classical working, reference and counter electrodes with dimensions of few $\mathrm{cm}$ have been replaced with flexible printed working, reference and counter electrodes with dimensions of few $\mathrm{mm}$, requiring only few $\mu \mathrm{L}$ of sample. In addition, the cost largely decreases from ca. $500 €$ to about $1 €$. Without doubt, printed biosensors have improved the life of diabetic patients, thanks to the printed electrochemical biosensor analysing their glucose in the blood at home with a simple finger prick, instead of going to hospital for more invasive analyses [26].

A butyrylcholinesterase biosensor based on a screen-printed electrode was developed by our group for the detection of nerve agents in the liquid and gas phases using a portable potentiostat. In detail, screen-printed electrodes were modified with Prussian Blue to detect thiocholine, the enzymatic by-product of butyrylcholinesterase at $+200 \mathrm{mV}$ vs. Ag/ AgCl pseudoreference. Being the butyrylthiocholine hygroscopic, the stability of the substrate was studied by investigating the effect of nitrogen flow in delivering a stable room temperature substrate. The optimized biosensor was tested using a portable potentiostat that is commercially available with Sarin and VX standard solutions, showing detection limits of $10 \mathrm{ppb}$ and $18 \mathrm{ppb}$, respectively. Furthermore, this biosensor demonstrated the capability of measuring Sarin in the gas phase by exposing the wet biosensor with phosphate buffer to Sarin gas. The effect of incubation time was evaluated by studying the incubation time from $30 \mathrm{~s}$ up to $10 \mathrm{~min}$ at concentrations of $0.1 \mathrm{mg} / \mathrm{m}^{3}$ and $0.5 \mathrm{mg} / \mathrm{m}^{3}$ of Sarin gas, demonstrating that only $30 \mathrm{~s}$ of incubation time are needed to detect Sarin at the concentration of $0.1 \mathrm{mg} / \mathrm{m}^{3}$ [27]. This biosensor was also configured to be embedded with a sampling prototype constituted of an electrochemical cell, a little fan for sampling air, and an electronic circuit for applying the potential, registering the current, turning on-off the fan, and giving an alarm if the signal decreases by $20 \%$, delivering a smart lab on a chip (Figure 3B). In detail, the biosensor was inserted in the cell by adding the substrate by a syringe. The detection of nerve agents in the gas phase was accomplished because the fan is able to sample 20-25 L of air/min by flowing the air into the electrochemical cell and enriching the working solution by nerve agents. This prototype encompasses an electronic 
circuit that is able to manage the fan and the miniaturized potentiostat by using (i) an analogic section for applying the potential $(+200 \mathrm{mV})$ followed by an input I/V amplifier for converting the input current signal into the output voltage signal and a low-pass filter to exclude the transient frequency disturbs, (ii) a digital section with an A/D converter for an input stage of the microcontroller. Paraoxon was used as a simulant and was tested at a concentration of 1 ppm for 12 times, always giving the switch-on of the alarm. Furthermore, blank solution did not cause any alarm, thus demonstrating the suitability of the device [28]. Screen-printed electrodes were also used to evaluate the sensitivity of different biocomponents, namely recombinant, electric eel, and bovine erythrocytes origin acetylcholinesterase, observing that human recombinant acetylcholinesterase seemed to be the most sensitive toward the inhibition by Sarin with a limit detection of $0.45 \times 10^{-8} \mathrm{~mol} / \mathrm{L}$ [29]. The same group developed a biosensing system using a platinum screen-printed electrode and acetylcholinesterase from electric eel in a solution to test Sarin, Soman, Tabun, and VX with the limits of detection of $7.41 \times 10^{-12} \mathrm{~mol} / \mathrm{L}$ for Sarin, $6.31 \times 10^{-12} \mathrm{~mol} / \mathrm{L}$ for Soman, $6.17 \times 10^{-11} \mathrm{~mol} / \mathrm{L}$ for Tabun, and $2.19 \times 10^{-11} \mathrm{~mol} / \mathrm{L}$ for VX, respectively [30].

Yoon et al. [31] used screen-printed electrodes to immobilize the acetylcholinesterase enzyme by cross-linking with glutaraldehyde and bovine serum albumin. This biosensor was then inserted in an enzymatic chamber on the microfluidic chip, fabricated using polymethylmethacrylate as the material to develop a lab on a chip for the detection of nerve agents. Using acetylthiocholine chloride as the substrate, thiocholine was monitored at a constant applied voltage of $0.1 \mathrm{~V}$ using a working electrode modified with cobalt phthalocyanine as the electrochemical mediator. The miniaturization of the device can be used for nerve agent detection as nerve agents are able to inhibit acetylcholinesterase enzymes.

Wang's group reported the first solid-contact fluoride screen-printed electrode for the detection of G-Serie nerve agents using organophosphorus acid anhydrolase as a biocomponent [32]. The detection relies on the capability of organophosphorus acid anhydrolase to break the P-F bond of the G-type nerve agents releasing detectable fluoride ions. The potentiometric biosensor was tested with diisopropyl fluorophosphates as a nerve agent simulant, reaching a dynamic range of 250-3000 $\mu \mathrm{M}$ and any interference when methyl paraoxon, methyl parathion, phenol, and aniline were analysed.

\section{Paper-Based Printed Devices}

Paper-based electrochemical (bio)sensors have recently acquired huge interest by the scientific community due to their sustainable features in terms of plastic-free measure and low cost. In addition, the measurements using paper-based biosensors can be carried out by unskilled personnel and these devices overcome the major drawbacks of microfluidic devices, including the requirement for micropumps, the bubble issues, and high costs for microfluidic pattern fabrication. A further added value in the defence contest relies on the capability of being incinerated after the measure, reducing the management of the waste contaminated with chemical warfare agents. As is well known, when a drop of water wets the paper, the water flows in the cellulosic network, and it also wets the electrical contacts and hinders the correct electrochemical measure. To overcome this drawback, we exploited the wax printing technique to easily create the hydrophilic region surrounded by the hydrophobic one to contain the working solution within the electrochemical cell. As an example, I report a paper-based bioassay for the detection of mustard agents using a portable instrument (Figure 3C(a)) [33]. For the manufacturing of paper-based screenprinted electrodes, the hydrophobic zone was printed onto office paper sheets, using a ColorQube 8580 Xerox printer, and treated at $100{ }^{\circ} \mathrm{C}$ for $2 \mathrm{~min}$ to let the wax homogeneously permeate the paper, producing the hydrophobic pattern designed. Then, the three electrodes were printed by using the screen-printing technique (Figure $3 \mathrm{C}(\mathrm{b})$ ). For mustard agent detection, choline oxidase enzyme was used as a biocomponent, measuring the degree of inhibition with an office paper-based electrochemical sensor bulk modified with Prussian Blue nanoparticles and carbon black with the overriding goal of measuring the enzymatic by-product $\mathrm{H}_{2} \mathrm{O}_{2}$ at a low applied potential by the chronoamperometric 
mode. This bioassay was conceived to work in a drop in the presence of choline oxidase and chemical warfare agent. It was successfully applied for the measurement of sulphur mustard Yprite with a detection limit of $0.9 \mathrm{mM}$.

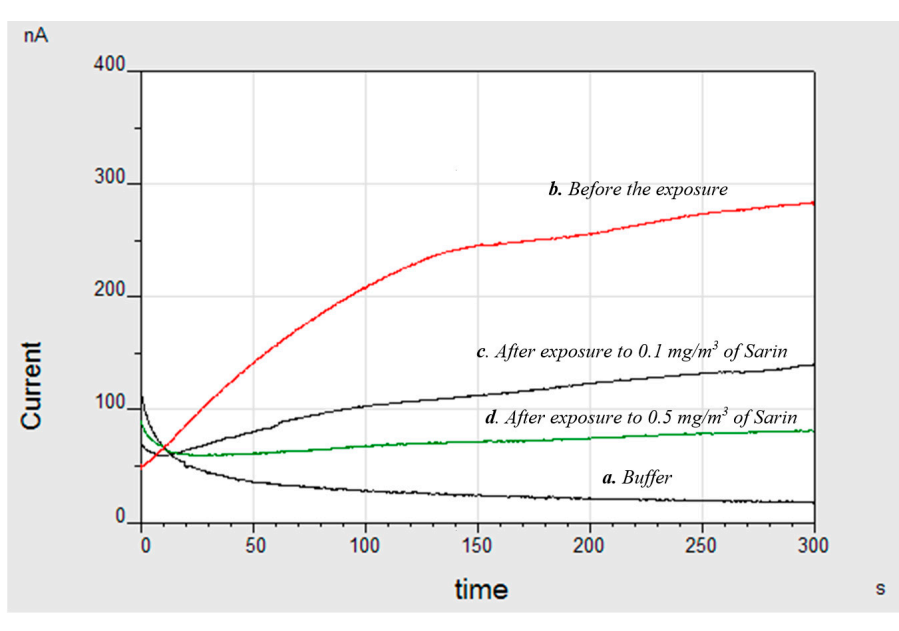

(A)

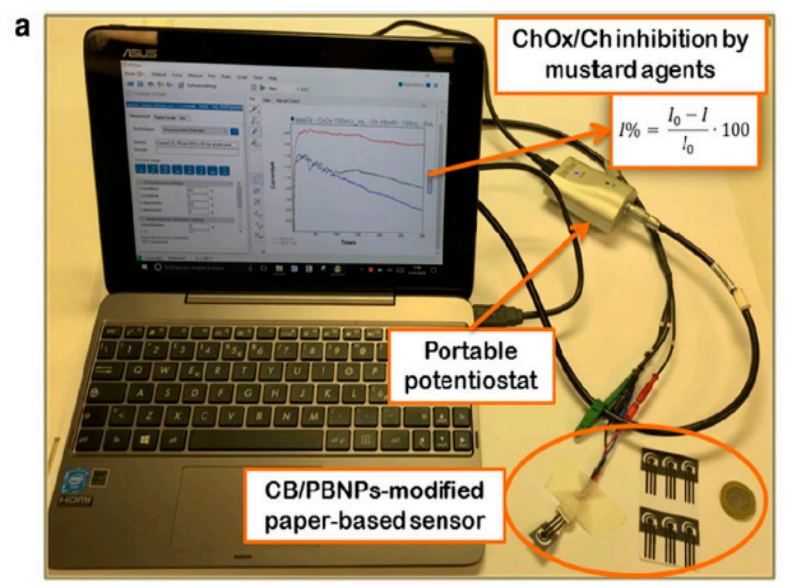

b (a) Pattern designing

(b) Wax printing
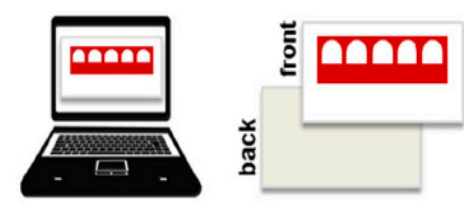

(c) Thermal treatment

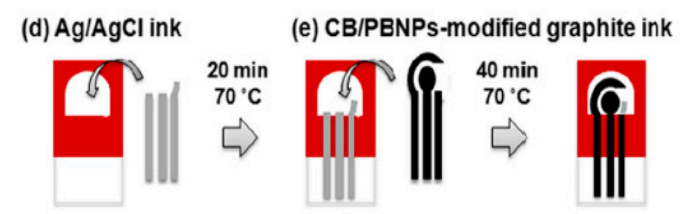

(C)

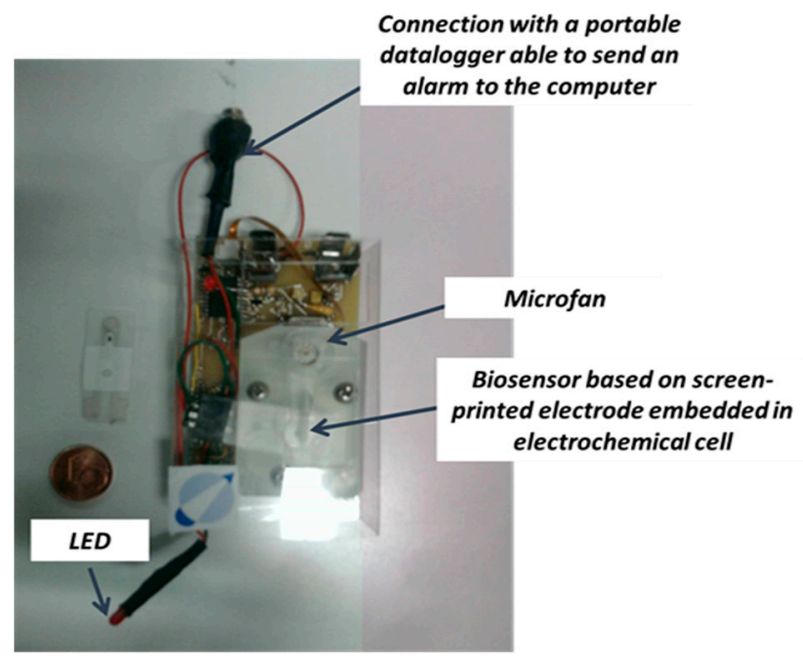

(B)
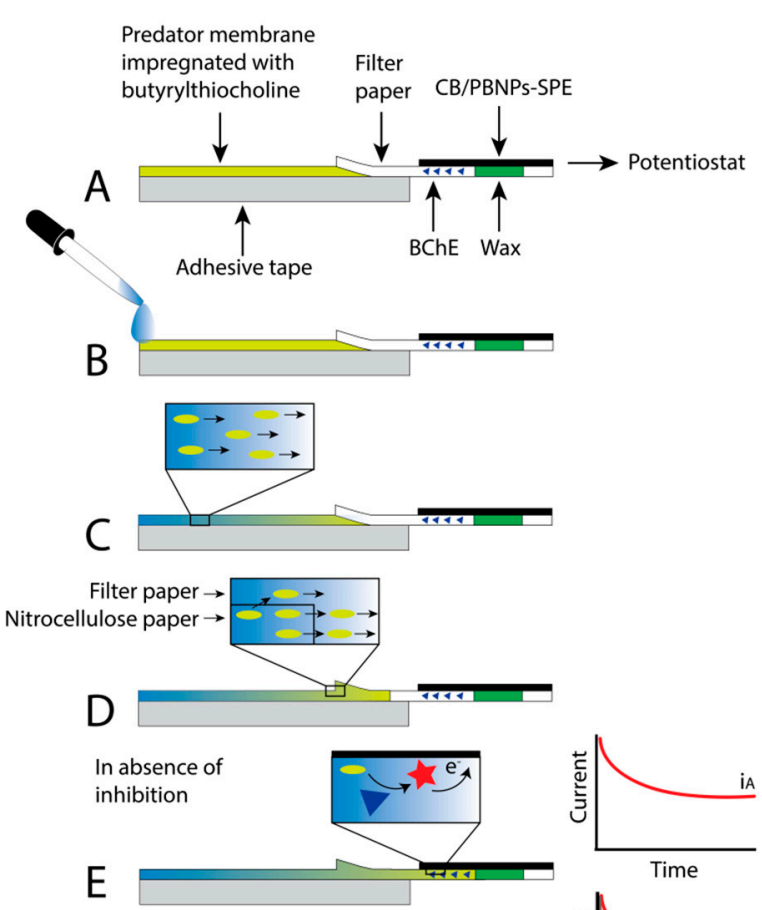
If $\mathrm{BChE}$ is inhibited
by paraoxon
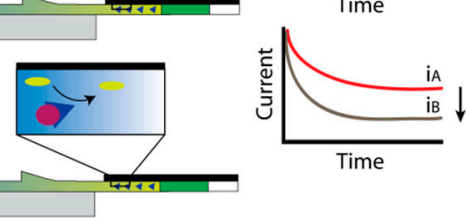

$\mathrm{F}$

(D)

Figure 3. (A) Amperograms using the screen-printed electrodes modified with Prussian blue and butyrylcholinesterase before and after the exposure to Sarin gas [27]. (B) Screen-printed based butyrylcholinesterase biosensor integrated into a lab on a chip [28]. (C) Paperbased screen-printed electrodes as a platform to detect mustard agents using choline oxidase as a biocomponent. (a-e) procedural steps for the realisation of wax-printed office paper serigraphic printing of conductive inks [33]. (D) Paper-based screen-printed electrode loaded with butyrylcholinesterase to detect paraoxon as a nerve agent simulant using the following steps (A-F) [34]. 
The first paper-based biosensor for reagent-free analysis of nerve agents was reported by our group, thanks to the combination of a strip of nitrocellulose membrane loaded with the substrate and a paper-based test screen-printed electrode functionalized with butyrylcholinesterase [34]. As the paper-based device loaded with the reagents was able to carry out a single measure, the measurement of nerve agent simulant was carried out by using two platforms that compared the non-inhibited chronoamperometric signal to the inhibited one. In detail, the blank signal was obtained by adding $10 \mu \mathrm{L}$ of distilled water on the edge of the Predator ${ }^{\circledR}$ membrane where butyrylthiocholine was adsorbed (Figure $3 \mathrm{D}(\mathrm{B})$ ). Then, the water flow pushed butyrylthiocholine toward the test area (Figure $3 \mathrm{D}(\mathrm{C})$ ), wetting the electrochemical cell where the enzyme with the phosphate buffer salts were loaded (Figure 3D(D)). When the water reached the testing area (ca. $30 \mathrm{~s}$ ), we waited for $2 \mathrm{~min}$ for the enzymatic reaction, producing the enzymatic by-product thiocholine (Figure 3D(E)). To measure paraoxon concentration, the testing area was firstly loaded with $5 \mu \mathrm{L}$ of the nerve agent simulant. After that, the device response was measured by following the procedure reported above, observing the decrease of the signal due to the decrease of enzyme activity (Figure $3 \mathrm{D}(\mathrm{F})$ ). This reagent-free device demonstrated the capability of detecting paraoxon, taken as nerve the agent simulant, down to $3 \mu \mathrm{g} / \mathrm{L}$.

\section{Wearable-Based Biosensors as Cross-Cutting Devices}

As reported by the World Economic Forum, by 2030, the very nature of diseases will be further disrupted by technology. The fourth industrial revolution will ensure that humans live longer and healthier lives, so that the hospitals of the future will become more like NASCAR pit-stops rather than inescapable black holes. You will go to the hospital to be patched up and put back on track, revolutionizing healthcare from hospital to "homespital" [35]. Currently, commercially available wearable sensors are aimed at physical sensing to monitor physiological parameters, but they do not provide any information at the molecular level (chemical sensing), which is also a key issue in the defence field.

Harnessing the principle of the choline oxidase based-bioassay, we developed a wearable and reagent-free biosensor, suitable for the on-site detection of both liquid and airborne mustard agents, exploiting filter paper to design a 3D structured origami-ePAD (Figure 4A). In detail, an electrochemical cell was developed onto the first layer of the origami by printing the conductive inks to realize the electrodes as well as to load the choline oxidase enzyme, and in the second layer, the electrolyte salts as well as the choline substrate were pre-loaded by exploiting the adsorptive properties of filter paper. Then, the measurements were carried out by assembling the origami layers, allowing for reaction within the pre-loaded reagents. The monitoring of choline oxidase enzyme was carried out using a filter paper-based sensor to detect sulphur mustard in the liquid phase, as well as in the gas phase, obtained by aerosolising sulphur mustard with a nebulizer. In detail, the origami-like biosensor was successfully tested for the rapid and real-time detection of sulphur mustard with detection limit equal to $1 \mathrm{mM}$ and $0.019 \mathrm{~g} \times \cdot \mathrm{min} / \mathrm{m}^{3}$ for the liquid and gas phase, respectively. The results achieved demonstrated the applicability of paper-based origami-inspired ePAD for ready-to-use wearable sensors for the monitoring of substances into the liquid as well as the gas phases [36].

Wang's group developed the first wearable skin and textile-worn biosensors for the continuous monitoring of nerve agents in the vapour-phase using organophosphate hydrolase (Figure 4B). This electrochemical biosensor was fabricated with elastomeric inks to deliver a flexible device integrated with an electronic interface able to maintain the functionality under mechanical stress and to send the data to a mobile device by wireless data transmission. By detecting the enzymatic by-product nitrophenol product in square wave voltammetry, the epidermal tattoo and textile sensors allowed for linearity over the 90-300 $\mathrm{mg} / \mathrm{L}$ range and detection limit of $12 \mathrm{mg} / \mathrm{L}$, demonstrating the suitability as a rapid warning device for personal exposure to nerve-agent vapours [37]. The same group developed a potentiometric tattoo biosensor for real-time on-body quantification of G-type nerve agent simulant by using a $\mathrm{pH}$-sensitive polyaniline sensor combined with 
organophosphate hydrolase as a biocomponent. This biosensor demonstrated a linearity between $20-120 \mathrm{mM}$ using a nebulizer solution of nerve agent simulant diisopropyl fluorophosphates, with a limit of quantification of around $10 \mathrm{mM}$ [38].

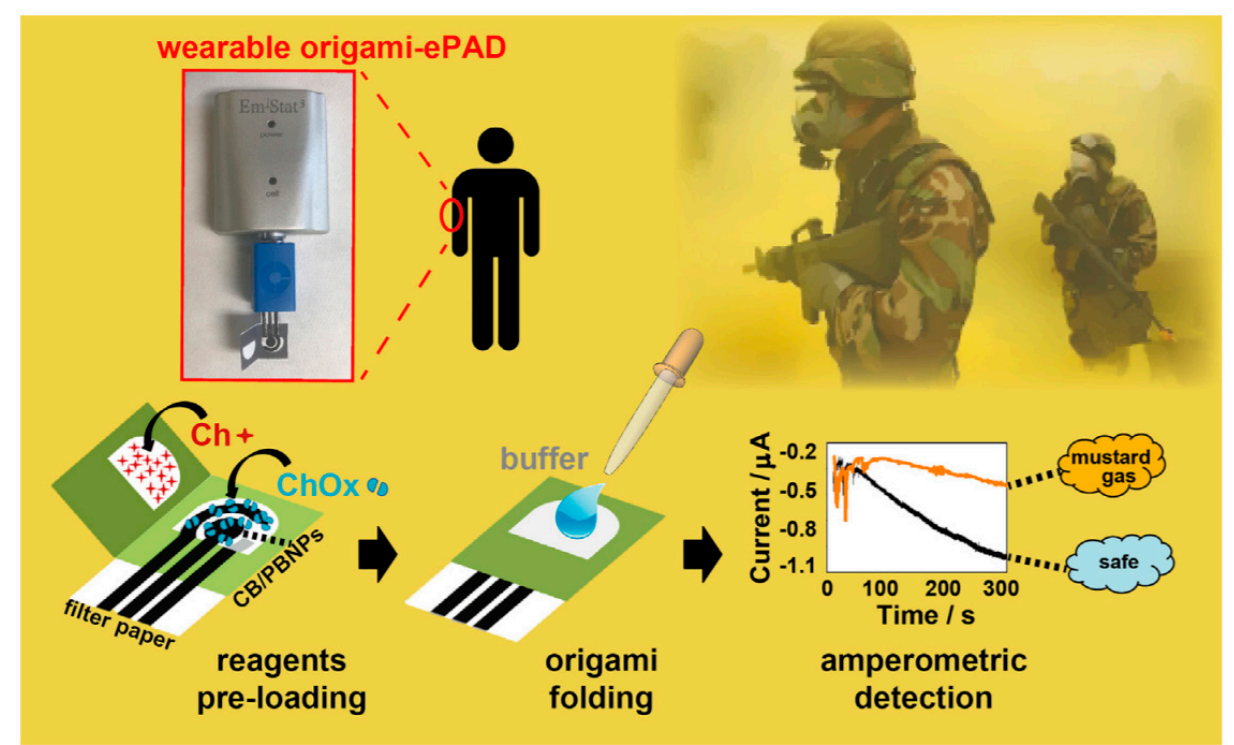

(A)
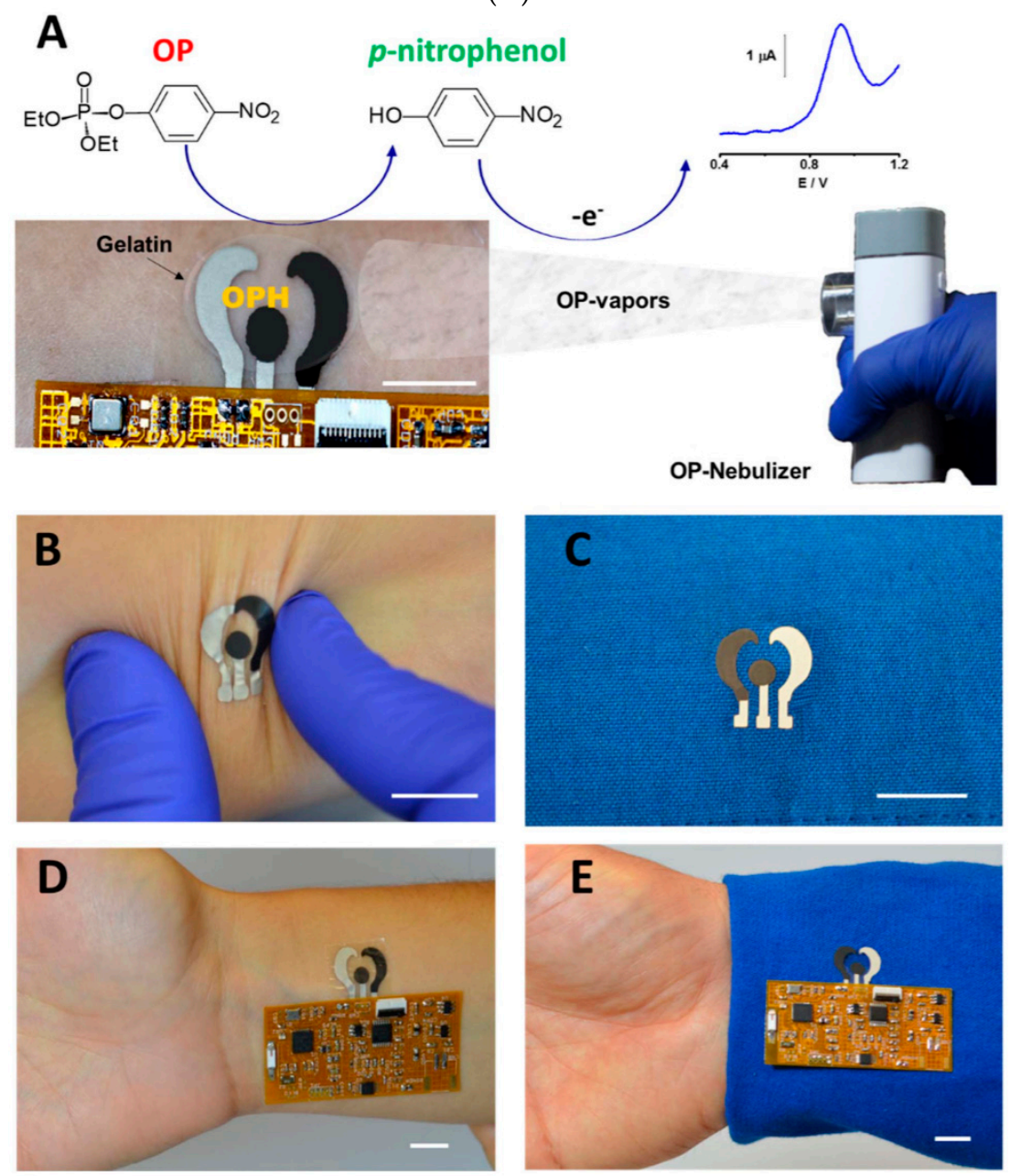

(B)

Figure 4. Cont. 

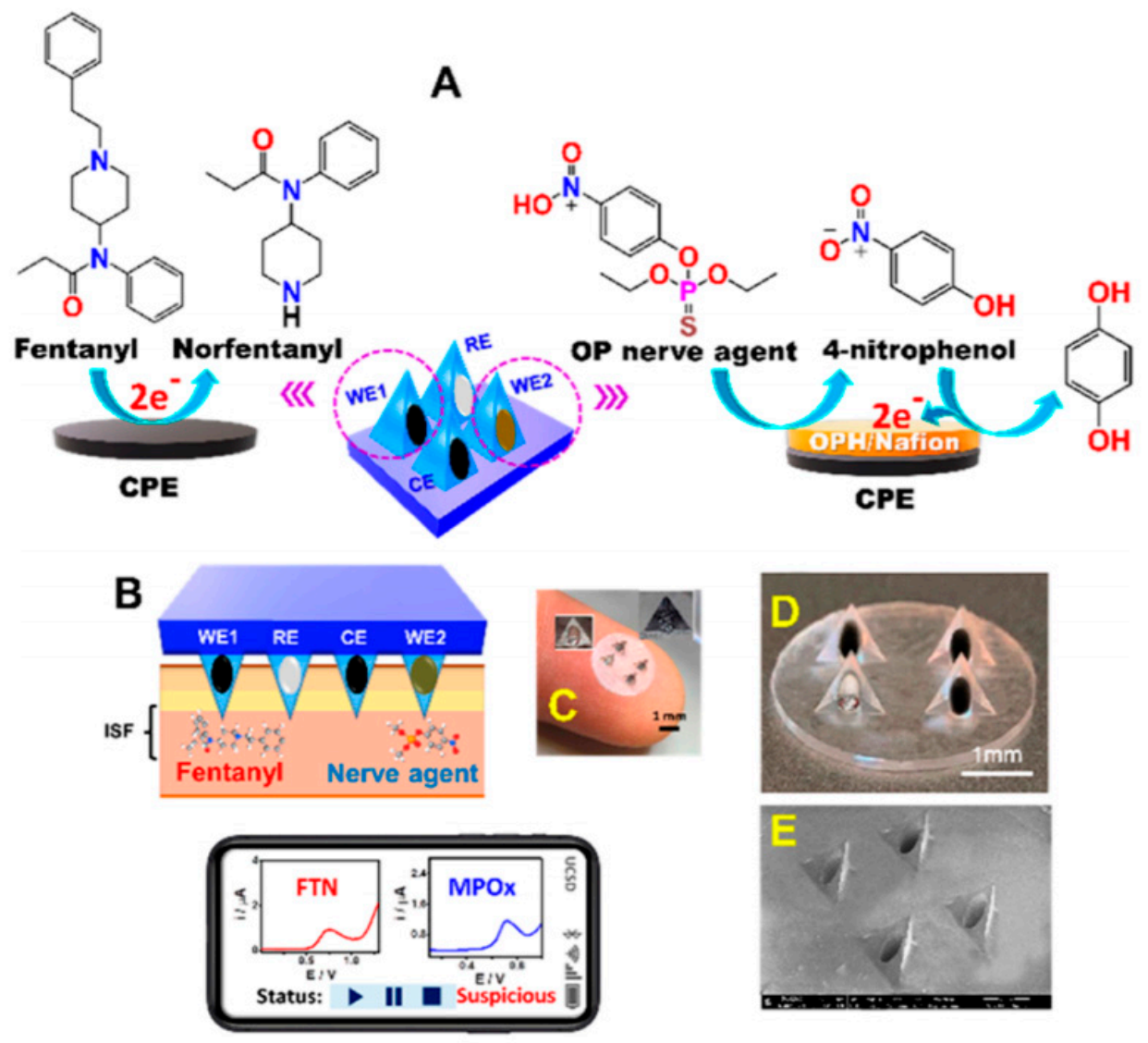

(C)

Figure 4. (A) Wearable origami paper-based choline oxidase-biosensor for mustard agents [36]. (B) Wearable skin and textile-worn biosensor for the continuous monitoring of nerve agents in the vapour-phase [37]. (C) Microneedle sensor array for detecting nerve agents and opioids [39].

The novel approach using a wearable microneedle sensor array to distinguish between opioid overdose and nerve agent poisoning was reported in the Journal of American Chemical Society in 2020 by the same group [39]. The microneedle array was fabricated by using a hollow microneedle working electrodes allowing (i) for direct voltammetric detection of fentanyl-based on oxidative dealkylation of the piperidine tertiary amine and norfentanyl production with a peak at $+0.7 \mathrm{~V}$, and (ii) for square wave voltammetry of the organophosphate hydrolase-by product, i.e., p-nitrophenol using methyl paraoxon as a nerve agent simulant, with a peak at ca. $+0.72 \mathrm{~V}$ (Figure $4 \mathrm{C}$ ). The detection of methyl paraoxon demonstrated a detection limit of $10 \mu \mathrm{M}$ with good operational stability (i.e., $90 \%$ of its original response), testing $100 \mu \mathrm{M}$ methyl paraoxon by 12 repetitive measurements at $10 \mathrm{~min}$ intervals. Furthermore, the applicability of this device was demonstrated in morphine and norfentanyl, demonstrating the possibility of useful, continuous monitoring of drugs of abuse and nerve agents.

\section{Conclusions}

The cross-cutting technologies, including nanomaterial and printing technologies, have paved the way for the development of smart and miniaturized analytical tools for the onsite measurement of chemical warfare agents. The printing technologies allowed us to deliver miniaturized and easy-to-use analytical tools with the features needed in the defence context. In addition, as disposable sensors are well suitable for nerve agents using cholinesterase enzyme, they require the reactivation in cases of classical electrochemical cells. The presence of nanomaterial has boosted the fabrication of the devices with improved sensitivity to match the requirements for the detection of chemical warfare agents 
at low concentrations. Furthermore, wearable biosensors have opened a new research line in this sector, enlarging the application of this technology beyond the biomedical field. I am confident that, in the future, the integration of these types of analytical tools with IoT will be the main driver of the smart management of data and deliver useful and high-throughput analyses.

Funding: This research received no external funding.

Institutional Review Board Statement: Not applicable.

Informed Consent Statement: Not applicable.

Data Availability Statement: Data sharing not applicable. No new data were created or analyzed in this study. Data sharing is not applicable to this article.

Conflicts of Interest: The author declares no conflict of interest.

\section{References}

1. Thévenot, D.R.; Toth, K.; Durst, R.A.; Wilson, G.S. Electrochemical biosensors: Recommended definitions and classification. Biosens. Bioelectron. 2001, 16, 121-131. [CrossRef]

2. Guilbault, G.G.; Kramer, D.N.; Cannon, P.L., Jr. Electrical Determination of Organophosphorous Compounds. Anal. Chem. 1962, 34, 1437-1439. [CrossRef]

3. Arduini, F.; Amine, A.; Moscone, D.; Palleschi, G. Biosensors based on cholinesterase inhibition for insecticides, nerve agents and aflatoxin B1 detection (review). Microchim. Acta 2010, 170, 193-214. [CrossRef]

4. Gogol, E.V.; Evtugyn, G.A.; Marty, J.L.; Budnikov, H.C.; Winter, V.G. Amperometric biosensors based on nafion coated screenprinted electrodes for the determination of cholinesterase inhibitors. Talanta 2000, 53, 379-389. [CrossRef]

5. Escarpa, A. Food electroanalysis: Sense and simplicity. Chem. Rec. 2011, 12, 72-91. [CrossRef]

6. Charitidis, C.A.; Georgiou, P.; Koklioti, M.A.; Trompeta, A.-F.; Markakis, V. Manufacturing nanomaterials: From research to industry. Manuf. Rev. 2014, 1, 11. [CrossRef]

7. Joshi, K.A.; Tang, J.; Haddon, R.; Wang, J.; Chen, W.; Mulchandani, A. A Disposable Biosensor for Organophosphorus Nerve Agents Based on Carbon Nanotubes Modified Thick Film Strip Electrode. Electroanal. Int. J. Devoted Fundam. Pract. Asp. Electroanal. 2005, 17, 54-58. [CrossRef]

8. Arduini, F.; Cinti, S.; Mazzaracchio, V.; Scognamiglio, V.; Amine, A.; Moscone, D. Carbon black as an outstanding and affordable nanomaterial for electrochemical (bio)sensor design. Biosens. Bioelectron. 2020, 156, 112033. [CrossRef] [PubMed]

9. Della Pelle, F.; Angelini, C.; Sergi, M.; Del Carlo, M.; Pepe, A.; Compagnone, D. Nano carbon black-based screen printed sensor for carbofuran, isoprocarb, carbaryl and fenobucarb detection: Application to grain samples. Talanta 2018, 186, 389-396. [CrossRef]

10. Deroco, P.B.; Fatibello-Filho, O.; Arduini, F.; Moscone, D. Electrochemical determination of capsaicin in pepper samples using sustainable paper-based screen-printed bulk modified with carbon black. Electrochim. Acta 2020, 354, 136628. [CrossRef]

11. Mazzaracchio, V.; Tomei, M.R.; Cacciotti, I.; Chiodoni, A.; Novara, C.; Castellino, M.; Scordo, G.; Amine, A.; Moscone, D.; Arduini, F. Inside the different types of carbon black as nanomodifiers for screen-printed electrodes. Electrochim. Acta 2019, 317, 673-683. [CrossRef]

12. Talarico, D.; Arduini, F.; Constantino, A.; Del Carlo, M.; Compagnone, D.; Moscone, D.; Palleschi, G. Carbon black as successful screen-printed electrode modifier for phenolic compound detection. Electrochem. Commun. 2015, 60, 78-82. [CrossRef]

13. Talarico, D.; Arduini, F.; Amine, A.; Moscone, D.; Palleschi, G. Screen-printed electrode modified with carbon black nanoparticles for phosphate detection by measuring the electroactive phosphomolybdate complex. Talanta 2015, 141, 267-272. [CrossRef] [PubMed]

14. Cinti, S.; Neagu, D.; Carbone, M.; Cacciotti, I.; Moscone, D.; Arduini, F. Novel carbon black-cobalt phthalocyanine nanocomposite as sensing platform to detect organophosphorus pollutants at screen-printed electrode. Electrochim. Acta 2016, 188, 574-581. [CrossRef]

15. Silva, T.A.; Moraes, F.C.; Janegitz, B.C.; Fatibello-Filho, O. Electrochemical Biosensors Based on Nanostructured Carbon Black: A Review. J. Nanomater. 2017, 2017, 1-14. [CrossRef]

16. Portaccio, M.; Di Tuoro, D.; Arduini, F.; Moscone, D.; Cammarota, M.; Mita, D.; Lepore, M. Laccase biosensor based on screenprinted electrode modified with thionine-Carbon black nanocomposite, for Bisphenol A detection. Electrochim. Acta 2013, 109, 340-347. [CrossRef]

17. Arduini, F.; Palleschi, G. Disposable electrochemical biosensor based on cholinesterase inhibition with improved shelf-life and working stability for nerve agent detection. In Portable Chemical Sensors; Springer: Dordrecht, The Netherlands, 2012; pp. 261-278.

18. Arduini, F.; Majorani, C.; Amine, A.; Moscone, D.; Palleschi, G. Hg2+ detection by measuring thiol groups with a highly sensitive screen-printed electrode modified with a nanostructured carbon black film. Electrochim. Acta 2011, 56, 4209-4215. [CrossRef]

19. Arduini, F.; Forchielli, M.; Amine, A.; Neagu, D.; Cacciotti, I.; Nanni, F.; Moscone, D.; Palleschi, G. Screen-printed biosensor modified with carbon black nanoparticles for the determination of paraoxon based on the inhibition of butyrylcholinesterase. Microchim. Acta 2015, 182, 643-651. [CrossRef] 
20. Lee, J.H.; Park, J.Y.; Min, K.; Cha, H.J.; Choi, S.S.; Yoo, Y.J. A novel organophosphorus hydrolase-based biosensor using mesoporous carbons and carbon black for the detection of organophosphate nerve agents. Biosens. Bioelectron. 2010, 25, 1566-1570. [CrossRef]

21. Colozza, N.; Mazzaracchio, V.; Kehe, K.; Tsoutsoulopoulos, A.; Schioppa, S.; Fabiani, L.; Steinritz, D.; Moscone, D.; Arduini, F. Development of novel carbon black-based heterogeneous oligonucleotide-antibody assay for sulfur mustard detection. Sens. Actuators B Chem. 2021, 328, 129054. [CrossRef]

22. Barron, E.S.G.; Bartlett, G.R.; Baker Miller, Z. The effect of nitrogen mustards on enzymes and tissue metabolism. J. Exp. Med. 1948, 87, 489-501. [CrossRef] [PubMed]

23. Karyakin, A.A. Prussian blue and its analogues: Electrochemistry and analytical applications. Electroanal. Int. J. Devoted Fundam. Pract. Asp. Electroanal. 2001, 13, 813-819. [CrossRef]

24. Cinti, S.; Arduini, F.; Vellucci, G.; Cacciotti, I.; Nanni, F.; Moscone, D. Carbon black assisted tailoring of Prussian Blue nanoparticles to tune sensitivity and detection limit towards $\mathrm{H}_{2} \mathrm{O}_{2}$ by using screen-printed electrode. Electrochem. Commun. 2014, 47, 63-66. [CrossRef]

25. Arduini, F.; Scognamiglio, V.; Covaia, C.; Amine, A.; Moscone, D.; Palleschi, G. A choline oxidase amperometric bioassay for the detection of mustard agents based on screen-printed electrodes modified with Prussian blue nanoparticles. Sensors 2015, 15, 4353-4367. [CrossRef] [PubMed]

26. Newman, J.D.; Turner, A.P.F. Home blood glucose biosensors: A commercial perspective. Biosens. Bioelectron. 2005, 20, $2435-2453$. [CrossRef]

27. Arduini, F.; Amine, A.; Moscone, D.; Ricci, F.; Palleschi, G. Fast, sensitive and cost-effective detection of nerve agents in the gas phase using a portable instrument and an electrochemical biosensor. Anal. Bioanal. Chem. 2007, 388, 1049-1057. [CrossRef]

28. Arduini, F.; Neagu, D.; Dall'Oglio, S.; Moscone, D.; Palleschi, G. Towards a Portable Prototype Based on Electrochemical Cholinesterase Biosensor to be Assembled to Soldier Overall for Nerve Agent Detection. Electroanalysis 2012, 24, 581-590. [CrossRef]

29. Pohanka, M.; Binder, J.; Kuca, K. Sarin Assay using Acetylcholinesterases and Electrochemical Sensor Strip. Def. Sci. J. 2009, 59, 300-304. [CrossRef]

30. Pohanka, M.; Adam, V.; Kizek, R. An acetylcholinesterase-based chronoamperometric biosensor for fast and relia-ble assay of nerve agents. Sensors 2013, 13, 11498-11506. [CrossRef]

31. Yoon, Y.J.; Li, K.H.H.; Low, Y.Z.; Yoon, J.; Ng, S.H. Microfluidics biosensor chip with integrated screen-printed electrodes for amperometric detection of nerve agent. Sens. Actuators B Chem. 2014, 198, 233-238. [CrossRef]

32. Goud, K.Y.; Teymourian, H.; Sandhu, S.S.; Tostado, N.; Mishra, R.K.; Moore, L.C.; Harvey, S.P.; Wang, J. OPAA/fluoride biosensor chip towards field detection of G-type nerve agents. Sens. Actuators B Chem. 2020, 320, 128344. [CrossRef]

33. Colozza, N.; Kehe, K.; Popp, T.; Steinritz, D.; Moscone, D.; Arduini, F. Paper-based electrochemical sensor for on-site detection of the sulphur mustard. Environ. Sci. Pollut. Res. 2018, 1-12. [CrossRef] [PubMed]

34. Cinti, S.; Minotti, C.; Moscone, D.; Palleschi, G.; Arduini, F. Fully integrated ready-to-use paper-based electrochemical biosensor to detect nerve agents. Biosens. Bioelectron. 2017, 93, 46-51. [CrossRef] [PubMed]

35. Healthcare in 2030: Goodbye Hospital, Hello Home-Spital. Available online: https://www.weforum.org/agenda/2016/11/ healthcare-in-2030-goodbye-hospital-hello-home-spital/ (accessed on 12 January 2021).

36. Colozza, N.; Kehe, K.; Dionisi, G.; Popp, T.; Tsoutsoulopoulos, A.; Steinritz, D.; Moscone, D.; Arduini, F. A wearable origami-like paper-based electrochemical biosensor for sulfur mustard detection. Biosens. Bioelectron. 2019, 129, 15-23. [CrossRef] [PubMed]

37. Mishra, R.K.; Martín, A.; Nakagawa, T.; Barfidokht, A.; Lu, X.; Sempionatto, J.R.; Wang, J. Detection of vapor-phase organophosphate threats using wearable conformable integrated epidermal and textile wireless biosensor systems. Biosens. Bioelectron. 2018, 101, 227-234. [CrossRef]

38. Mishra, R.K.; Barfidokht, A.; Karajic, A.; Sempionatto, J.R.; Wang, J.; Wang, J. Wearable potentiometric tattoo biosensor for on-body detection of G-type nerve agents simulants. Sens. Actuators B Chem. 2018, 273, 966-972. [CrossRef]

39. Mishra, R.K.; Goud, K.Y.; Li, Z.; Moonla, C.; Mohamed, M.A.; Tehrani, F.; Wang, J. Continuous opioid monitoring along with nerve agents on a wearable microneedle sensor array. J. Am. Chem. Soc. 2020, 142, 5991-5995. [CrossRef] 